\title{
Accreditation of Australian Urban Planners: Building Knowledge and Competence
}

\author{
Alan March $^{\mathrm{a}}$, Anna Hurlimann ${ }^{\mathrm{a}}$ \& Jennifer Robins ${ }^{\mathrm{a}}$ \\ Faculty of Architecture Building and Planning, The University of Melbourne Australia \\ Published in (2013) Accreditation of Australian urban planners: building knowledge and competence, \\ Australian Planner, 50:3, 233-243, DOI:10.1080/07293682.2012.745887
}

\begin{abstract}
There is an ongoing need to assess the relevance of current models of planning education. In light of changes to the accreditation of planners in Australia made in 2010, this paper critically examines whether the modifications are more suited to developing professional competence in graduates. We present a framework for critical appraisal of accredited professional degrees. This framework is based on theory that asserts the need for professionals to have both declarative (knowledge) and functional (competency) skills. Planning education accreditation standards for Australia, the United States of America, and the United Kingdom are analysed and compared against this framework. Our findings indicate significant differences between the accreditation documents in the three countries. Additionally, our results indicate that the changes made to the Australian accreditation standards in 2010 have significantly improved its ability to guide the professional education of planners. We identify that further research is needed to measure the actual competence of graduates to determine appropriate standards and to verify existing competence.
\end{abstract}

\section{INTRODUCTION}

Planning is a complex and challenging profession. Practicing planners have historically come from diverse backgrounds (ranging from engineering, surveying, building and architecture). However, the formal education of Australian planners only began in 1949 with the first course offered at the South Australian School of Mines and Industries (Hamnett, 1999). Over the past decade a number of new Australian planning schools have emerged, with diverse curricula at undergraduate and postgraduate levels. This diversity, matched with external forces, has led to questions about the core skills that planners require, alongside deeper debates regarding the structure of Australian higher education itself.

The Planning Institute of Australia (PIA) is the peak professional body for urban planning in Australia. PIA accredits planning degrees across the country based on their 'Accreditation Policy for the Recognition of Australian Planning Qualifications' (PIA, 2010). As at June 2012, courses accredited by PIA total 22 at the undergraduate level, and 27 at the postgraduate level. PIA's accreditation policy was updated in 2010, after PIA formally identified a need to re-examine its professional accreditation processes and criteria (Gurran et al. 2008). While the review was conducted in a systematic manner with several opportunities for input (Bosman et al 2011), it occurred against a backdrop of planning and educational issues.

Firstly, institutional changes have occurred, such as some Australian universities changing course structures to facilitate broad learning at undergraduate level, in parallel with professional qualifications being delivered only at postgraduate level. Secondly, the necessity of using professional accreditation 
to guide education raises concerns. Critics such as Sandercock (1997) view professionally-driven planning education as reductionist, causing knowledge and understanding to be understood as little more than shopping lists of skills, methods and competencies. Alternatively, accreditation is viewed by others as a means for ensuring key competencies, alongside allowing flexibility for educators in the way they deliver learning experiences (Dalton, 2001). Thirdly, the recent widening of the Australian planning profession to include a greater diversity of skill types has increased the range of people calling themselves planners. This is matched by PIA's recognition of different prior educational backgrounds of planners, and they have set stricter standards for specialist chapters. Added to this are periodic shortages and surpluses of urban planners in Australia and internationally, and greater acknowledgment of environmental and social imperatives and changes in the overall educational landscape. As noted by Bosman et al (2011) in their consideration of wider changes occurring in the Australian higher education landscape, there is an increasing tendency to treat education as a marketable commodity, encouraging competition between planning schools. They argue that increased competition between schools has resulted in changed approaches, that are not necessarily carefully considered, such as use of internships and work practicums to make graduates work-ready. These wider changes, and tendencies to deliver education in larger classes which are unsuited to studio-based learning, add to questions as to whether accreditation sufficiently guides graduate outcomes.

The main aim of this research is to analyse whether the changes made to the PIA accreditation document in 2010 are likely to be beneficial to developing the professional competence of Australian Urban Planners. Competence is more fully defined in subsequent sections, however, it is understood generally as the ability to make independent judgements informing actions in non-routine circumstances (Kirschner \& Van Vilsteren, 1997). To provide context, we begin with an overview of challenges for planning This is followed by a short section which sets out a view of professional education, arguing that developing competency is central to appropriate education for planners, and that particular care is needed for its development in students in the university system.

A core distinction in educational theory between modes of learning and teaching is used in this paper: declarative (knowledge) and functional (competency) skills. Using this understanding as a base, a framework for assessing accreditation standards is then presented, centred upon determining whether accreditation standards assist in the development of competence. We compare our analysis of the Australia planning accreditation documents (2002 and 2010) with those of two additional countries to provide international context. The paper concludes that the accreditation standards do provide improved direction for the development of planners' professional competency, and that the framework provides educational principles that can inform educators during the ongoing design and delivery of overall courses of study and/or individual units or subjects. We argue that this represents a shift in educational emphasis in the accreditation of Australian planning.

\section{CHALLENGES FOR PLANNING}

To examine planning education, it is useful to first briefly consider planning's nature and key challenges. While practitioners and academics struggle to define urban and regional planning beyond simply describing the activities currently carried out in a given place by planners (Campbell \& Fainstein, 1996; March, 2007) the general realm of planning's endeavours is definable. The kind of planning we are considering here focuses upon finding ways to favourably influence the manner in which built and natural environments are used, conserved, developed, managed or organised. It is acknowledged that planning must also have an ongoing orientation to the future (Bolan, 1974: 15), even while action must always occur in the present, in circumstances resulting from the past. 
Urban planning offers possibilities for future spatial outcomes that avoid or reduce the impacts of mistakes, remediate existing problems and achieve outcomes that are not possible without prior organisation and coordination. Accordingly, planning systems are typically oriented to the favourable arrangements of natural resources, agriculture, housing, industry, and social equity, to name a few (Healey, 1997: 4). As such, a wide range of matters present themselves as worthy of planners' attention. In fact, so many matters might be worthy of our concern, that planning can be enlarged to the point where it ironically loses its essence (Wildavsky, 1973). One means of dealing with this, while contested by some (eg Dalton, 2001; Sandercock, 1997), is to determine the core areas of concern to planners and to seek influence over collective decision making, thus understanding planning as one force in spatial decisions (Steiner, 1979: Ch2). While listing all challenges faced by planning is not possible here, the broad topics identified above indicate the sheer scale of the ongoing challenges which planners have to grapple with when practising their profession. These challenges are now coupled with increased institutional complexity (Buxton et al. 2003), and decreased citizen trust in government and institutions (Kasperson et al. 1992). This means that planners cannot simply be "trained" in a static way, since the nature of the problems they deal with are complex and require innovative and ongoing responses.

\section{PROFESSIONAL EDUCATION - DECLARATIVE $A N D$ FUNCTIONAL}

An increasingly strong feature of contemporary urban planning is that planners are predominantly university educated professionals. Accordingly, it is necessary to consider how professional attributes are developed in the university setting. The ideal of professionalism is founded on the knowledge and practise of specialised skills, based on practitioners' membership in a professional organisation. It depends upon at least some level of self-regulation that the professions can exert over their own membership, conduct, and expertise (Friedson, 2001: 1). This orientation to higher-order skills, relative autonomy over members' conduct, and status, is theoretically matched by the understanding that professions, and the individual professionals within them, work towards the public interest (Koehn, 1994: 147; Macdonald, 1995: 167). Professions can be defences against societal 'threats' such as ill health, mercantile discord or lawlessness (Durkheim, 1957). With specific regard to urban planning, the causes of 'problems' are complex (Rittel \& Webber, 1973), with diverse clients (Campbell \& Marshall, 2002), including various funders, diverse 'publics', politicians, interest groups, government agencies and even future generations (Evans \& Rydin, 1997).

Professionals are meant to be distinct from others by practising intellectual and non-routine thinking, based upon considerable discretionary consideration and action. To successfully exercise discretion, professionals must have superior levels of abstract knowledge based upon formal learning (Friedson, 2001: 34-5), described as 'reflecting in action' (Schön, 1983), or as practical application of higherorder thinking, without simply being "told what to do" (Broadbent, et al. 1997: 10). This means that professions and professionals are also meant to semi-independently evaluate both the way they work, and the results of that work. This means that critical self-appraisal (for individuals and the profession itself) is vital to professionalism, in parallel with the ability to perform in ways that will evolve and adapt over time as circumstances change.

One view of accreditation standards is that they are a sort of quality assurance, representing a method by which a profession 'controls its own work', in terms of the abilities possessed by graduates, at least (Broadbent, et al. 1997: 10). That is, they can provide 'guidance' in the way particular knowledge types can be achieved and overall values maintained in providing direction in teaching, such as studios (Bosman et al 2011) or other means. A lack of appropriate guidance may erode the ability of accreditation to necessarily lead to true professionalism in graduates (Wise, 2005). Proper attention to teaching that achieves planning competence would go a considerable way to achieving a better 
'theory/practice nexus', identified as a significant current gap in the Australian context (Gurran et al., 2008: 18). This means it is appropriate to consider accreditation documents' value in providing guidance in teaching, even while this may necessarily be quite flexible. Indeed, Bloom's taxonomy has shown for over 50 years that good teaching is best achieved by establishing objectives and linking these with the method of teaching appropriate to the outcome required (Marzarno \& Kendall, 2007). If accreditation standards include this linking of various learning elements to objectives, they can provide guidance for the design of overall degrees and the individual subjects and tasks within (Carey et al 2001).

However, it must be acknowledged that professional learning presents challenges for higher education, if the types of knowledge imparted are understood from the perspective of educational theory (Leinhardt, et al. 1995: 403). One reason for this is because practised professional knowledge is based to a large extent on functional ability (competence), while universities tend to find it easier and more economically efficient to teach declarative knowledge (Biggs \& Tang, 2007), particularly as class sizes increase and teaching loads for academics become greater alongside decreased use of studio learning (Bosman et al, 2011; Coiacetto et al 2011).

Declarative knowledge is knowing about things and being able to declare these back in various ways, for example: 'who was Ebenezer Howard?' Functional or procedural knowledge, however, is based upon the performance of tasks, building upon declarative knowledge: 'design a subdivision using Garden City principles in contemporary regulatory circumstances'. Both knowledge types are important as the basis for professional competency, but as identified by Entwistle and Entwistle (1997), universities by their nature, can tend to focus upon teaching that encourages declarative knowledge development. The issue is that training of professionals in universities is often oriented to developing students' abilities to 'label, differentiate, elaborate and justify' when their practice life will actually be to 'execute, apply and prioritize' (Biggs \& Tang, 2007: 73). This does not necessarily mean that this is occurring in Australia's planning schools, but rather, that it is a key distinction worthy of attention to ensure professional competence, or to enhance existing levels of competence.

\section{THE DEVELOPMENT OF A FRAMEWORK FOR CRITICAL APPRAISAL OF PROFESSIONALLY ACCREDITED DEGREES}

The key research question we explore in this paper is as follows:

Does accreditation documentation for planning education in Australia support the ideal of developing both declarative and functional skills as the basis for professional competence?

In this section of the paper we develop a framework to test this research question. The framework focuses upon the distinction between declarative (knowledge) and functional (competency) skills. The distinction between declarative and functional skills is not necessarily clear in every instance, but falls within a continuum. The finer-grain categorisation of educational objectives offered by the seminal theoretical work of Bloom's Taxonomy (1956) illustrates this, and supports the categorisation used in this paper. The taxonomy organises learning objectives based on complexity, moving from 'low level' learning objectives (knowledge, comprehension and application) to 'high level' learning objectives (analysis, synthesis and evaluation). Recently updated by Anderson et al (2001) and Marzano and Kendall (2007), Bloom's taxonomy identifies details of the higher level learning objectives that address the functional skills and competence that Biggs and Tang (2007) argue as critical to professional 
practice (Anderson, 2001). Operationalization of these different learning modes in the structure of planning degrees presents educators with challenges to deliver subjects based variously on knowledge, skills and application of intellect. These debates will resonate particularly with discussions raised as to the proper role of studios, and with the integration of work placement in many degrees (Bosman et al 2011) and the need to establish measures of competencies in work placements (Coiacetto et al 2011) .

One mechanism that directly seeks to understand ways of developing skills via university education suitable for professionals in the European Union (EU) is commonly known as the Bologna Educational Accord (European Ministers Responsible for Higher Education [EMRHE], 2005). The Bologna cycles had many objectives (all of which may not be appropriate in the Australian setting), including discerning between Bachelors, Masters and Higher Degrees. Importantly, the Bologna Accord directly discerns between different learning types, particularly with respect to declarative knowledge and functional skills. It matches Bloom's (1956) higher level learning objectives and Biggs and Tang's (2007) functional skills, providing a more structured means of assessing educational frameworks, such as accreditation standards, in terms of professional competence.

Importantly, it is not suggested here that Australian planning education needs to be delivered in the format directly represented by the Bologna cycles - that would mean professional planning education is only delivered at Masters level ${ }^{1}$. Rather, it is argued that The Framework of Qualifications for the European Higher Education Area (EMRHE, 2005: 2) sets out a base for more clearly understanding the range of learning types necessary for professional education, whether these are delivered at the Bachelor or Master level. The document provides a clear description of professional studies, as a pathway to professional competencies, doctoral level studies, and to allow access for 'returning learners' (Davies, 2009: 12).

Our framework for the critical appraisal of professionally accredited degrees (shown in Table 1) is based in the principles of the Bologna Cycles, putting aside the Bachelor versus Masters distinction. The framework sets out a continuum of learning from understanding a field of knowledge or expertise (1-5 in Table 1), through to higher order learning oriented to the critical application of, and contribution to a specialist field of expertise, such as a profession (6-10 in Table 1). The Bologna higher order distinguishing characteristics of graduating students appropriate to the professions are "original idea development" and "application in their given field", often within a research context.

Table 1: Framework for the Critical Appraisal of Accredited Professional Degrees

\begin{tabular}{|c|c|c|}
\hline 1 & Knowledge and understanding that includes some knowledge at the forefront of the field & \multirow{9}{*}{ Declarative } \\
\hline 2 & The application of that knowledge by devising arguments and solving problems & \\
\hline 3 & $\begin{array}{l}\text { Gathering and interpreting data to inform judgement while reflecting on social, scientific or ethical } \\
\text { issues }\end{array}$ & \\
\hline 4 & Communication of the above to specialist and non-specialist audiences & \\
\hline 5 & To have skills necessary for taking on further study in reasonably autonomous way & \\
\hline 6 & Original idea development and application, often within research context & \\
\hline 7 & $\begin{array}{l}\text { Within the given field, applying knowledge, understanding and problem solving in new or unfamiliar } \\
\text { environments within broader, often multidisciplinary contexts }\end{array}$ & \\
\hline 8 & $\begin{array}{l}\text { Integrating knowledge and handling complexity to formulate judgments with incomplete or limited } \\
\text { information, while reflecting on social and ethical responsibilities linked to applying their knowledge } \\
\text { and judgment in the field }\end{array}$ & \\
\hline 9 & $\begin{array}{l}\text { Communicating their conclusions, and the knowledge and rationale underpinning these, to specialist } \\
\text { and non-specialist audiences }\end{array}$ & \\
\hline
\end{tabular}

\footnotetext{
${ }^{1}$ Bologna qualifications in the first cycle are typically Bachelor degrees, second cycle are Master level (profession focused), and third are Doctoral level, with allowance for some limited intermediate steps (EMRHE, 2005).
} 
$\mathbf{1 0}$ Learning skills allowing continued study in a manner that may be largely self-directed or autonomous

(Adapted from Bologna Cycles, see EMRHE 2005)

Achievement of the full range of characteristics outlined above relies upon particular concepts being applied in a given degree. In particular, as students move through their studies, greater emphasis upon the competencies in the latter parts of the table is required - the development of functional skills, in addition to declarative knowledge. While declarative knowledge types vary, they are characterised by learning, remembering and or reproducing knowledge, as opposed to carrying out higher order processes upon or with them (Kirschner \& Van Vilsteren, 1997). Functional skills, however, consist of actions able to be measured according to persons' ability to carry out professional tasks successfully. These may also be actions 'on knowledge' that lead to developing new knowledge or new cognitive representation. Alternatively, functional skill actions 'with knowledge' may be directed to verifiable objects, ultimately with the effect of being demonstrated in reality: writing a research report, conducting an experiment, building a model, or producing new experience or knowledge about reality (Crombag et al. 1979).

Professional graduates are required to go even further, to apply declarative and functional skills to the point of having competency in that field (represented by 5-10 in Table 1). Competency can be understood simply as the ability 'to do something', and it is often used to mean this in the case of routine non-professional work. However, when considered in professional education, competence takes on greater intellectual depth and implication, involving 'judgements, values, self-confidence to take risks, and a commitment to learn from experience' (Kirschner \& Van Vilsteren, 1997). Competence relies on professionals having skills that are specialized problem-solving abilities, suitable for the profession, which also develop new knowledge and procedures.

\section{AUSTRALIAN URBAN PLANNING EDUCATION STANDARDS IN INTERNATIONAL CONTRAST}

The framework outlined above provides a basis for analysing whether professional education standards required by accreditation documents are oriented to developing the competency of graduates (e.g whether they encourage the development of the whole range of skills addressed in the framework's continuum). This conforms to the ideals of professionalism as competent and intellectual use of knowledge and skills.

We acknowledge the limitations of analysing accreditation documents only. A clear research need in Australia is an assessment of what is actually delivered in 'professional' planning degrees in terms of a split between declarative and functional skills. Notwithstanding, this paper seeks to establish the first examination of the principles underlying accreditation standards themselves. We argue that if accreditation is a standard against which degrees may be measured, it must firstly establish tests to ensure graduates are equipped to act as professionals. Secondly, accreditation must provide some indication of what professional education might be, at the level of a whole degree or individual subjects, allowing not just tests for accreditation, but guidance for educators.

We compare Australia's 2002 and 2010 accreditation standards to that of the UK and the USA. These countries were chosen for a number of reasons, including: they are in English, are from planning bodies with a high profile internationally, and are used in settings that allow meaningful comparison. General features of each of these accreditation documents can be found in Table 2.

Table 2: Details of Urban Planning Degree Accreditation in Australia, the UK and the USA

\begin{tabular}{|l|l|l|l|l|}
\hline Information & Australia Former & Australia Current & UK & USA \\
\hline
\end{tabular}




\begin{tabular}{|l|l|l|l|l|}
\hline Year published & 2002 & 2010 & 2004 & 2006 \\
\hline Publisher & PIA & PIA & RTPI & PAB \\
\hline Title & $\begin{array}{l}\text { Education Policy for } \\
\text { recognition of } \\
\text { Australian Planning } \\
\text { Qualifications }\end{array}$ & $\begin{array}{l}\text { Accreditation Policy for } \\
\text { the Recognition of } \\
\text { Australian Planning } \\
\text { Qualifications }\end{array}$ & $\begin{array}{l}\text { Policy Statement on } \\
\text { Initial Planning } \\
\text { Education }\end{array}$ & $\begin{array}{l}\text { Criteria and Procedures } \\
\text { of the Planning } \\
\text { Accreditation Program }\end{array}$ \\
\hline $\begin{array}{l}\text { Document length } \\
\text { (pages) }\end{array}$ & 14 & 25 & 16 & 46 \\
\hline $\begin{array}{l}\text { Minimum degree } \\
\text { length (years) }\end{array}$ & 4 & $\begin{array}{l}\text { 4 undergraduate, and/or } \\
\text { 2 postgraduate }\end{array}$ & 4 & 4 \\
\hline
\end{tabular}

In the UK, the Royal Town Planning Institute (RTPI) completed a review of its policies, practices and requirements related to education, training and qualifications in 2003 (RTPI Education Commission, 2003). The accreditation policy outlines three elements of education whereby graduates can apply to become Charted Town Planners: spatial planning education, specialist planning education and assessment of professional competence - a 'structured experience in the workplace' (RTPI, 2004: p.3). The document identifies that spatial planning education programs 'should be designed to provide a broad understanding of the main principles relevant to the making of place and the mediation of space.' Specialist planning education programs 'should be designed to explore ideas, perspectives and debates to a considerable depth in one distinctive area of planning.' The policy encourages planning schools to develop their own particular identity and specialisations, while achieving the professional standards set in the professional document.

In the USA, planning degrees are accredited by a 'Planning Accreditation Board' (PAB 2006). The planning accreditation process is a cooperative undertaking jointly sponsored by three organisations: the American Institute of Certified Planners, the Association of Collegiate Schools of Planning, and the American Planning Association. The document outlining accreditation requirements is extensive. The specific curriculum criteria required for accreditation includes four major components that outline knowledge, skills and values that qualify graduates of accredited degree programs to enter professional planning practice. The twenty six criteria against which accreditation are assessed are divided into four subsections (PAB 2006: 4.2.1-4): 1) understanding human settlements, 2) knowledge of historical and contemporary planning practice, 3 ) skills needed to practice, and 4) understanding the different values and ethical standards affecting the practice of planning.

In Australia, neither the former or current accreditation documents specify a precise planning curriculum. Instead, they intentionally provide flexibility for individual schools to develop their own identities. The former document stipulated five knowledge, fourteen skill, and two professional ethics requirements. Key required knowledge areas were: an understanding of the purpose and methods of planning; the natural and cultural environment; the political, legal and institutional contexts of planning; relevant social, economic and environmental principles; and indigenous Australian cultures. Skills included problem definition and objective formulation; plan making; mediation and conflict resolution; research methods; and understanding and responding to cultural diversity and difference (PIA 2002). Importantly, paragraph 29 of the document declared: 'The criteria described in this PIA Education Policy for Recognition of Australian Planning Qualifications are for guidance and are not mandatory' (Planning Institute of Australia, 2002).

The new Australian accreditation document differs in four main ways. First, it more explicitly acknowledges a diversity of qualification pathways that might be used to deliver an accredited degree, but does set "typical" modes for delivery (p.6). Undergraduate specialist degrees are to be equivalent to the full time study of: eight semesters, including a substantial independent project; or, six semesters 
full time followed by a two semester honours; or, six semesters, followed by a two semester postgraduate program. At the postgraduate level it suggests: at least a three semester postgraduate planning program, if preceded by six semesters of cognate undergraduate study; or, four semesters in a specialist planning program.

Second, the new accreditation document emphasises that planning schools must demonstrate how graduates develop skills leading to competencies (p.9). In parallel, it encourages programs to develop their own identities, while integrating staff research into teaching. Third, the policy directly seeks that accreditation encourages objectives-based learning, using performance tests to allow flexibility of delivery while maintaining certainty of delivery (p.8,9). This is intended to guide educators, accreditation boards, and students themselves during learning. Fourth, the document more explicitly requires: generic capabilities and competencies; core curriculum competencies; and supporting knowledge areas (p.8-12). A graduate from a planning program must possess (via the course structure and outcomes) generic "Capabilities and Competencies" (p. 9) that are based in functional skills, such as "problem identification" and "research". The core curriculum focuses upon statements of competency including professionalism, plan-making, and governance. These statements each have performance outcomes that schools are required to demonstrate. These performance standards vary between knowledge of matters such as "diversity of populations served" and "capacity to gather qualitative and quantitative data... to analyse it and to communicate its relevance...." (p.10, 11 italics added).

\section{METHOD OF ANLAYSIS}

The contents of each of the four accreditation documents were independently analysed by each of the three authors. The analysis compared the level of apparent conformance each document had with the Framework outlined in Table 1. Content analysis principles advocated by Babbie (2008) and Neuendorf (2002) were followed, including: developing operational definitions for key variables (as found in table 3); and deciding on a scope of analysis (we chose each document in its entirety, rather than a sample from each). A matrix was developed for the analysis, based on the framework set out in Table 1. Each accreditation document was rated according to its:

1. Level of accordance with the Framework for critical appraisal of accredited professional degrees $(\mathrm{A})$

2. Provision of a clear test or indication of how criteria are met (I)

Because of the necessarily subjective nature of such assessment (in comparison to simple coding and counting of content), scales (detailed in Table 3) were developed for the assessment of the accreditation documents against the Framework.

Table 3 - Explanation of scales developed for the assessment of accreditation documents

\begin{tabular}{|l|l|l|}
\hline Rating & Accordance with Framework (A) & Implementation Guidance (I) \\
\hline 1 & $\begin{array}{l}\text { Not referred to, or referred to in a } \\
\text { limited way }\end{array}$ & Little apparent guidance \\
\hline 2 & $\begin{array}{l}\text { Some reference/s or summated } \\
\text { through document }\end{array}$ & $\begin{array}{l}\text { Some guidance, but lacking in some way such as: lacking } \\
\text { clarity of meaning, or provision of explanation, examples or } \\
\text { illustration; or in testable measures }\end{array}$ \\
\hline 3 & Fully and clearly referred to & $\begin{array}{l}\text { Clear guidance with explanation, examples or illustration and } \\
\text { indicating testable measures and manner of integrating } \\
\text { educational outcomes }\end{array}$ \\
\hline
\end{tabular}


Each of the documents were analysed and subsequently rated according to the scales presented in Table 3 above, by each of the authors. The results were pooled. Only minor differences between the researchers occurred. In such instances a discussion was held to determine a final, agreed upon rating.

\section{ACCREDITATION - BUILDING KNOWLEDGE AND COMPETENCE}

Table 4 presents the results of the accreditation document analysis using the matrix developed. At face value, each of the professional accreditation standards addresses the broad categories of substantive learning one would expect of an urban planner. However, when attention is paid to the different knowledge types required by the document, considerable variation is revealed. This examination derives from the assumption that education oriented to professional competence requires building upon declarative knowledge to higher level functional skills, culminating in professional-level abilities. It is asserted that, while individual schools must take considerable responsibility for this, accreditation standards also need to specify this progression of competence, to maintain certainty of outcomes. In addition, it is suggested that, while flexibility is desirable, it is not enough for accreditation standards to outline outcomes alone without some guidance.

Table 4 - Accreditation Documents' Accordance with Framework for Critical Appraisal of Accredited Professional Degrees: Australia, UK, and USA

\begin{tabular}{|c|c|c|c|c|c|c|c|c|}
\hline \multirow[t]{3}{*}{ Criteria } & \multicolumn{4}{|c|}{ Australia } & \multirow{2}{*}{\multicolumn{2}{|c|}{$\mathbf{U K}$}} & \multirow{2}{*}{\multicolumn{2}{|c|}{ USA }} \\
\hline & \multicolumn{2}{|c|}{ Former } & \multicolumn{2}{|c|}{ Current } & & & & \\
\hline & $\mathbf{A}^{*}$ & $I * *$ & $\mathbf{A}$ & I & $\mathbf{A}$ & I & $\mathbf{A}$ & I \\
\hline 1 & 3 & 2 & 2 & 2 & 3 & 3 & 3 & 3 \\
\hline 2 & 1 & 1 & 3 & 2 & 3 & 3 & 3 & 3 \\
\hline 3 & 1 & 1 & 3 & 2 & 3 & 3 & 3 & 3 \\
\hline 4 & 2 & 1 & 3 & 2 & 3 & 3 & 2 & 2 \\
\hline 5 & 1 & 1 & 2 & 2 & 2 & 1 & 3 & 3 \\
\hline 6 & 1 & 1 & 2 & 2 & 3 & 3 & 3 & 3 \\
\hline 7 & 1 & 1 & 2 & 2 & 2 & 1 & 2 & 2 \\
\hline 8 & 1 & 1 & 2 & 2 & 2 & 1 & 2 & 2 \\
\hline 9 & 1 & 1 & 3 & 2 & 2 & 2 & 2 & 2 \\
\hline 10 & 1 & 1 & 2 & 2 & 2 & 1 & 2 & 2 \\
\hline
\end{tabular}

$* \mathrm{~A}=$ Accordance with Framework for Critical Appraisal of Accredited Professional Degrees

**I $=$ Implementation Guidance. See Table 1 for the outcome details, and Table 3 for full details of the rating scales

At a broad level, the results suggest that the former Australian accreditation document rated the lowest of the four documents in terms of meeting the competency ideals. For example it rated poorly with regards to accordance with outcomes, and with provision of directions for implementation. On the contrary, the USA rated the highest. The new Australian document rates considerably better than the former. Overall, each of the documents rate higher in the lower order outcomes (declarative) criteria, than in higher order criteria oriented to competence.

The skills and knowledge areas outlined in the former Australian document reveal that they emphasised declarative knowledge far more than functional skills. Yet pure declarative knowledge alone is only one of the 10 criteria in the Framework, suggesting that it is highly important, but also that it is only a base upon which functional ability, as the essence of professional competence is developed.

Additionally, declarative knowledge fulfils only the first two of six knowledge types in the widely accepted new version of Bloom's Taxonomy of educational objectives (Marzarno \& Kendall, 2007). Accreditation is not the only measure of professional educational quality - universities and educators themselves play significant roles, as do continuing professional development requirements.

Significantly in this respect, the former Australian accreditation document itself offered no definition of 
what 'knowledge' and 'skills' are, which suggests that educators and accreditation boards previously had limited guidance in this respect.

A key concern across all of the accreditation documents was the need for flexibility for planning schools, balanced against the need for clear measures of whether the range of objectives set out are actually being achieved. The new Australian document clearly seeks to provide considerably greater guidance on functional skills. The UK and USA accreditation documents already deal with this to some extent, achieving medium ratings in the competency outcomes. For example, section 4.2.3 of the USA document sets out a number of planning skills, including graduates being able to:

use ideas about the creation of plans, programs or projects to prepare an individually crafted product for a specific planning purpose and audience; demonstrating skill and judgment preparing a planning project that meets minimum professional standards

The above example is an indication of demonstrable and testable aspects of professional skills that are set out in the document. Importantly, these qualities in graduates were joined in the accreditation documents themselves with some guidance as to the manner in which competence might be achieved via education. For example, in the case of the USA accreditation document, section 4.2 .3 (f) requires students (as just one of many abilities) to:

Use ideas about the creation of plans, programs or projects to prepare an individually crafted product for a specific planning purpose and audience; demonstrating skill and judgement preparing a planning project that meets minimum professional standards

'Professional standards' are understood to mean satisfying ethical concerns regarding competing interests, equity issues, democratic processes, and socio-historical-ecological concerns (4.2.4), along with the ability to apply these skills (4.2). This requirement, while setting a testable standard, also begins to elaborate on how students might achieve functional skills to a level of competence in keeping with the higher order education objectives such as 'metacognition' and 'self-system thinking' (Marzarno \& Kendall, 2007).

At this level of education, students are being required to develop an ability for self-awareness whereby the learner, and the self-directed ends to which skills are being put, is also under question. This specification contrasts with the reality that in many contexts, universities tend to find it easier and more economically efficient to teach declarative knowledge (Biggs \& Tang, 2007). Further, it develops overall functional skills into competence in planning, by requiring professionals to act in the public interest, and against 'threats' to society (Durkheim, 1957; Koehn, 1994: 147; Macdonald, 1995: 167), when the ends to which professional competence are directed become a key element of concern. The implication is that professionals' knowledge and skills must be turned towards achieving wider societal purposes.

When the nature of its professional context and the types of challenges faced are considered, it would seem that urban planning, more than any other profession, requires graduates to be able to develop innovative, context-specific solutions in changing circumstances. However, none of the documents explicitly set out the role of the planner as having the ability, intellectually, to develop ideas and to set new agendas as a professional. Thus, their potential as change agents is not explicitly facilitated or sought.

Using the Framework developed, which serves as a metric of a range of knowledge and skills types as students develop towards professional competence, allows understandings of the ways that accreditation might ensure the development of functional skills, in addition to declarative knowledge (Kirschner \& Van Vilsteren, 1997). This has provided a means to compare the nature of professional planning accreditation standards in Australia, the UK and the USA. In this test, the transition of Australian urban planning's accreditation to a much more functional professional orientation suggests 
that its future application may provide a useful measure of encouraging greater professional competence.

\section{CONCLUSIONS}

This paper examined Australian professional planning accreditation, as it changed in 2010, alongside that of the UK and the USA. It sought to determine whether accreditation documentation for planning education in Australia supports the ideal of developing both declarative and functional skills as the basis for professional competence. In order to do so, we developed a framework for Critical Appraisal of Accredited Professional Degrees, based on key educational theory. The Framework was used as a broad comparative tool to assess and compare accreditation documents in these three countries. However, the Framework can also be applied to the context of degrees outside the realm of planning, and outside Australia.

As detailed early in this paper, planning, as a project of collective action, seeks to favourably influence the circumstances of cities and regions. Planning is faced with acting in increasingly complex circumstances. Meeting these challenges requires professional planners to possess the competence to take action in complex and changeable circumstances. This means that new understandings and approaches to planning must continue to be developed. While the importance of university educators themselves cannot be overstated, the role of accreditation in ensuring that graduates are in the best position to meet ongoing challenges must also be recognised.

Our research found that accreditation, as a standard for professional education to meet these emerging challenges to planning, varies in the three countries examined. The research demonstrates how recent changes (2010) have significantly improved apparent shortcomings in the previous Australian standard (2002). It is argued that accreditation meeting criteria along the entire continuum of the Framework (addressing both declarative and functional skills) is more likely to provide a stronger basis for planning education, with wider knowledge transference benefits. The use of the principles encompassed in the Framework, alongside the key elements of educational theory on which it is based, can provide useful benchmarks for the improvement of university professional degree accreditation processes, and for educators themselves in developing individual subjects. This view assumes that education for professional roles must be oriented to developing greater intellectual depth to provide a base for the exercise of judgements and to deal with value-laden situations (Koehn, 1994: 147; Macdonald, 1995: 167). We argue that it is vital in accreditation standards to ensure that professional competence is developed in accredited degrees - ensuring that professionals are qualified to act in a role, as distinct from those who has simply studied a field.

Our findings indicate that the former Australian accreditation was previously oriented much more towards declarative knowledge, and had considerably less emphasis on ensuring the development of skills and competence than the equivalent UK and USA accreditation. Further, Australian accreditation previously provided much less guidance for educators as to how the range of skills might be developed - acknowledging that planning educators have generally been providing these in any case. The current standards represent a significant improvement in achieving competence according to the test applied here, and suggest ways in which the existing standards could be further enhanced. Further research is now required to consider whether the recent transition to emphasising functional knowledge will actually improve professional competence, and indeed whether educators will really use the detailed accreditation documents in the preparation of degrees and individual subjects, both in Australian and international contexts. 


\section{ACKNOWLEDGEMENTS \& DECLARATION}

The authors would like to acknowledge funding received from the University of Melbourne Provost Learning and Teaching Initiative Grant Scheme 2009. Thanks go to Lisa Feim, Romy Davidov and Sarah Oberklaid for research assistance provided. It should also be acknowledged that the paper benefitted significantly from the critical comments of the reviewers.

It is noted that Alan March drafted key elements of the current Australian accreditation standards, drawing on results of an earlier unpublished version of this paper presented to the Australian New Zealand Association of Planning Schools (2009), and subsequent invitation by the Planning Institute of Australia to its National Education Committee.

\section{REFERENCES}

Anderson, L. W., Krathwohl, D. R., Airasian, P. W., Cruikshank, K. A., Mayer, R. E., Pintrich, P. R., Raths, J., and Wittrock, M. C. (2001). A taxonomy for learning, teaching, and assessing: A revision of Bloom's taxonomy of educational objectives. Longman: New York.

Biggs, J., \& Tang, C. (2007). Teaching for Quality Learning at University (3rd ed.). New York: McGraw Hill.

Bloom, B. S. (1956). Taxonomy of educational objectives: the classification of educational goals. New York: D McKay \& Co.

Bolan, R. S. (1974). Mapping the Planning Theory Terrain. In O. R. Godschalk (Ed.), Planning in America: Learning from Turbulence (pp. 13-74): American Institute of Planners.

Bosman, C. Coiacetto, E \& Dredge, D. (2011): The shifting ground of Australian Higher Education through the lens of reflexive modernisation: compromising the quality of planning education? Australian Planner, 48:2, 72-83

Broadbent, J., Dietrich, M., \& Roberts, J. (1997). The End of the Professions? In J. Broadbent, M. Dietrich \& J. Roberts (Eds.), The End of the Professions: The restructuring of professional work (pp. 1-13). London: Routledge.

Buxton, M., Goodman, R., \& Budge, T. (2003). A failed experiment : the performance of the Victoria Planning Provisions and the new format planning schemes. Melbourne: School of Social Science and Planning, RMIT University.

Campbell, H., \& Marshall, R. (2002). Utilitarianisms Bad Breath: A re-evaluation of the public interest justification for planning. Planning Theory, 1(1), 163-187.

Campbell, S., \& Fainstein, S. (1996). Introduction: The Structure and Debates of Planning. In S. Campbell \& S. Fainstein (Eds.), Readings in Planning Theory. Cambridge: Blackwell.

Carey, J. O., Perrault, A. H., \& Gregory, V. L. (2001). Linking Outcomes Assessment with Teaching Effectiveness and Professional Accreditation. Academic Exchange, 5(1), 79-86.

Coiacetto, E. Jones, M. \& Jackson, J.T. (2011): How best to assess students' learning in work placements: moving beyond current practice, Australian Planner, 48:4, 270-280

Council of Europe. (2009). Bologna for Pedestrians. Retrieved 5 February 2009, 2009, from http://www.coe.int/t/dg4/highereducation/EHEA2010/BolognaPedestrians_en.asp\#P132_13851

Crombag, H. F., Chang, T. M., Drift, K. D., \& Vand der Moonen, J. M. (1979). Onderwijsmiddelen van de Open Universiteit: functies en kosten [Educational Materials for the Open University: functions and costs]. The Hague: Ministry of Education and Sciences.

Dalton, L. C. (2001). Weaving the Fabric of Planning As Education. Journal of Planning Education and Research, 20(4), 423-436.

Davies, H. (2009). Survey of Master Degrees in Europe. Retrieved 7 May 2009 
Department of Education Science and Training. (2006). The Bologna Process and Australia: Next Steps. Retrieved 9 May 2009, from http://www.dest.gov.au/NR/rdonlyres/D284E32F-98DD4A67-A3C2-D5B6F3F41622/9998/BolognaPaper.pdf

Durkheim, E. (1957). Professional Ethics and Civic Morals. London: Routledge and Kegan Paul.

Entwistle, N., \& Emntwistle, A. (1997). Revision and the experience of understanding: implications for teaching and studying in higher education. In F. Marton, D. Hounsell \& N. Entwistle (Eds.), The Experience of Learning. Edinburgh: Scottish Universities Press.

EMRHE. (2005). The framework of qualifications for the European Higher Education Area. Retrieved 8 May 2009, from http://www.bolognabergen2005.no/EN/BASIC/050520 Framework qualifications.pdf

Evans, B., \& Rydin, Y. (1997). Planning, Professionalism and Sustainability. In A. Blowers \& B. Evans (Eds.), Town Planning into the 21st Century. London: Routledge.

Friedson, E. (2001). Professionalism: the third logic. Chicago: University of Chicago Press.

Gurran, N., Norman, B., \& Gleeson, B. (2008). Planning Education Discussion Paper. Canberra: Planning Institute of Australia.

Hamnett, S. (1999). 50 Years of Planning Education in Australia. Australian Planner, 36(1), 5-6.

Healey, P. (1997). The Revival of Strategic Spatial Planning in Europe. In P. Healey, A. Khakee, A. Motte \& B. Needham (Eds.), Making Stretegic Spatial Plans. London: UCL Press.

Kasperson, R. E., Golding, D., \& Tuler, S. (1992). Social Distrust as a Factor in Siting Hazardous Facilities and Communicating Risks. Journal of Social Issues, 48(4), 161-187.

Koehn, D. (1994). The Ground of Professional Ethics. London: Routledge.

Leinhardt, G., McCarthy Young, K., \& Merriman, J. (1995). Integrating Professional Knowledge: the Theory of Practice and the Practice of Theory. learning and Instruction, 5, 401-408.

Macdonald, K., K. (1995). The Sociology of the Professions. London: Sage.

March, A. (2007). Institutional Impediments to Planning Professionalism in Victoria, Australia. International Planning Studies, 12(4), 367-389.

Marzarno, R. J., \& Kendall, J. S. (2007). The New Taxonomy of Educational Objectives. THousand Oaks California: Corwin Press.

PAB. (2006). Criteria and Procedures of the Planning Accreditation Program. Chicago: Planning Accreditation Board.

PIA. (2002). Education Policy for Recognition of Australian Planning Qualifications. Canberra: Planning Institute of Australia National Secretariat.

PIA (2004). National Enquiry into Planning Education and Employment. Canberra: Planning Institute of Australia.

PIA. (2010). Accreditation Policy for the Recognition of Australian Planning Qualifications' Canberra: Planning Institute of Australia National Secretariat.

Rittel, H., \& Webber, M. (1973). Dilemmas in a General Theory of Planning. Policy Sciences, 4, 155169.

RTPI. (2004). Policy Statement on Initial Planning Education. London: Royal Town Planning Institute. RTPI. (2003). Policy Statement on Initial Planning Education. Retrieved 25 May, 2009, from http://www.rtpi.org.uk/item/1638

Sandercock, L. (1997). The Planner Tamed. Australian Planner, 34(4), 90-95.

Schön, D. (1983). The Reflective Practitioner. New York: Basic Books.

Steiner, G. A. (1979). Strategic Planning: What every manager must know. New York: The Free Press. Wildavsky, A. (1973). If Planning is Everything, Maybe it's Nothing. Policy Sciences, 4, 127-153.

Wise, A. E. (2005). Establishing Teaching as a Profession: The essential role of professional accreditation. Journal of Teacher Education, 56(4), 318-331. 


\section{University Library}

\section{- M M I N E R VA A gateway to Melbourne's research publications}

Minerva Access is the Institutional Repository of The University of Melbourne

Author/s:

March, A; Hurlimann, A;Robins, J

Title:

Accreditation of Australian urban planners: building knowledge and competence

Date:

2013-01-01

Citation:

March, A., Hurlimann, A. \& Robins, J. (2013). Accreditation of Australian urban planners:

building knowledge and competence. AUSTRALIAN PLANNER, 50 (3), pp.233-243. https:// doi.org/10.1080/07293682.2012.745887.

Persistent Link:

http://hdl.handle.net/11343/59081 